5. Pavlovich, M.P., Imperialism and Struggle for Great Future Railway and Sea Routes: (Concerning the Question of the Reasons Behind the World War), 4th Edition, Leningrad: Gos. izd-vo, 1925 [in Russian].

6. Baranovskii, St., Indo-Volga Railroad, Niva, no. 34, pp. 536-539 [in Russian]. http:zerrspiegel.orientphil.uni-halle.de/i53.html; http://www.ruzgd.ru/indiya_volga.

shtml.

\title{
HIGH RISK ZONES ON FLOODS AND LANDSLIDES DISASTERS IN RWANDA
}

\author{
NSENGIYUMVA J.ean Baptiste ${ }^{1}$, Habiyaremye Gabriel ${ }^{2}$ \\ 1. \\ Ministry of Disaster management and Refugies Affairs, Directorate of Research and Public \\ Awareness, Kigali Rwanda \\ 2. Institute of lay Adventists of Kigali, Department of Emergency and Disaster Management \\ PoBox6392
}

\begin{abstract}
Disaster risk management as an issue at stake worldwide shifts its emphases from post disaster to pre-disaster phases. Management activities required in pre-disaster phases, such as risk assessment, hazard identification, preparedness or preventive and mitigation measures needs detailed information about hazard characteristics, social, economic, structural vulnerability and capacity. That information is not usually available in many different countries, as it is the case in Rwanda. Based on the international experiences and practices, knowledge of disaster prone areas can be assumed as an alternative for detailed information acquisition, thus contributing to effective disaster risk management.

Identification of disaster higher risk zones on floods and landslides, can lead to better understanding of disaster risk and putting in place measures for risk reduction. Consequently, as Rwanda is prone to natural hazards with lack of adequate information that is essential for effective disaster risk management, due to limited scientific researches; this study aims to address that gap. The results revealed that some areas of the North-Western parts of Rwanda are highly prone to floods and landslides, namely Burera, Musanze, Rulindo, Nyabihu, Ngororero and Rubavu Districts. This is aggravated by some triggering factors such as steep slopes, soil types, heavy rains, landuse Practices and others. Intensity and frequency of disaster events vary from district to district and this geographical dispersal confirms the non-spatial clustering (as confirmed by Moran's I analysis) of risks due to uneven level of Disaster vulnerabilities, coping capacities and available hazards whereby lack of normal distribution of hazards all over all Districts.
\end{abstract}

Keywords: Disaster, Risk zones, Floods, Landslides, Hazards

\section{DISASTER RISK AND CAPACITIES ASSESSMENT IN THE NORTH-WEST PARTS OF RWANDA}

\author{
1. Ministry of Disaster management and Refugies Affairs, Directorate of Research and Public \\ Awareness, Kigali Rwanda \\ 2. Institute of lay Adventists of Kigali, Department of Emergency and Disaster Management \\ PoBox6392
}

\begin{abstract}
The Republic of Rwanda is located in the Great lakes region of the central Africa. This landlocked country has historically suffered from periodic natural and manmade disasters, mainly in the form of droughts, floods and landslides impacting the agrarian economy and the country's efforts towards sustainable development and poverty reduction.

Vulnerability to Periodic natural disasters is a long term concern. The study therefore aims at conducting an assessment of disaster risks, vulnerabilities and coping capacities in Burera, Nyabihu and Musanze Districts affected floods and landslides in order to put in place mitigation strategies for disaster risks. Different methods and
\end{abstract}

